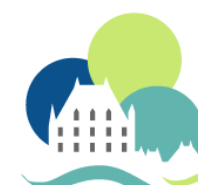

ISCAR 2017

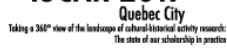

\title{
Practice of Teachers' Training on the Basis of the Ideas of Cultural and Historical Psychology of L. S. Vygotsky
}

\author{
Alexey S. Obukhov \\ Moscow State University of Psychology and Education \\ Moscow, Russia
}

\begin{abstract}
In Russia, new standards of education, which are built in many respects on the basis of the ideas of cultural and historical psychology, are accepted. It is natural that there has occurred a question of modernization of vocational training of the teacher who would not simply listen to or read about these ideas, but would work out their practical way of realization in their everyday practice, self-reflect this experience, embody trial action with children, and selfreflect it again. As the basic ideas of L. S. Vygotsky and his school of sciences, the basis of the concept of modernization of pedagogical education was formed through the following concepts: the development as mastering the culture; the concept of age and logics of an age periodization; a ratio of training and development in a zone of the next development; the change of a social situation of development and crises of a growing; the roundabout ways of development; the causal biography; cultural mediation of the development of the highest mental functions; etc. The fundamental principles of modernization of pedagogical education are the following: logics of creation of education "from an action to a thought" (a practical action with its video fixing - the criteria analysis of this action - the development of the theory describing action mechanisms - the following level of practical action) and social constructivism as the leading way of activity in the situation of uncertainty and variability. The experience of introduction of this model (about 2000 people) within three years has shown its efficiency.
\end{abstract}

Keywords : Russian education; Cultural and historical psychology; Teachers' training; L. S. Vygotsky; Concept of modernization of pedagogical education; ZDP. 
In 2016, the World Scientific Community widely celebrated the 120 anniversary since the birth of the outstanding scientist, "Mozart of psychology" (Tulmin, 1981) - Lev Semenovich Vygotsky (1896 - 1934). In Moscow and in many other countries a series of the actions devoted to judgment of scientific heritage of L. S. Vygotsky and his value for modern science and practice took place (https://vygotsky.hse.ru/). The last ten years of his life, the most productive in his scientific activity, from 1924 to 1934, L. S. Vygotsky worked in Moscow Pedagogical State University (MPSU). At that time, that institution was called Second Moscow State University, then Moscow State Teacher Training College named after A.S. Bubnov) - professor and the head of the department of the difficult childhood (http://выготский.pф/архивные-материалы/). MPSU not only reveres the memory of a great professor, but in recent years has made an attempt to build the training of students of pedagogical education on the basis of L. S. Vygotsky's psychological concept.

In the world, the works of L. S. Vygotsky are well known. They enter the obligatory set of texts while studying psychology and the adjacent scientific directions, especially pedagogical psychology, children's psychology, psycholinguistics, defectology, and art psychology. With a support on methodology of cultural and historical psychology, the researches are conducted not only in Russia and other countries - the former republics of the USSR that was brightly presented on round tables within the International network congress to the 120 anniversary of L. S. Vygotsky that took place in Armenia, Azerbaijan, Belarus, Kazakhstan, Uzbekistan (Sakharov, 2016). The researches in compliance with school of sciences of L. S. Vygotsky in Ukraine, in Georgia are known, in the countries of the Baltics where a number of scientists continue to act on the methodological basis and a semantic reference point in development of psychological science and student teaching, especially in the field of the developing training. Specialists in scientific heritage of L. S. Vygotsky work in many countries of Europe (Great Britain, Germany, Italy, Poland, Portugal, Finland, France, the Czech Republic, etc.), in Canada, in USA, in the countries of Latin America, Iran, Japan, etc.

There exist different approaches which L. S. Vygotsky's followers built and developed as educational systems, such as: the system of stage-by-stage formation of educational actions of P. Y. Galperin (Galperin, 1985), the system of developing of V. V. Davydov and D. B. Elkonin's training - (Davydov, 1996), the system of developing of L. V. Zankov's training (Zankov, 1985). These systems of training continue their development not only in Russia, but also in many schools of Ukraine, Belarus, Moldova, Latvia, Kazakhstan and other countries.

The realization of the ideas of L. S. Vygotsky defined the formation and development modern social constructivism in practice of education in Germany (Fthenakis, 2003) and in cognitive schools of Iran (Saeednia, 2011). Under the leadership of Vasilios Ftenakis in Bavaria, Baden-Württemberg and others land in Germany the development programs of preschool and primary education on the basis of cultural and historical psychology of L. S. Vygotsky. They worked out and implemented, first of all based on L. S. Vygotsky's ideas about a ratio of training and development, the zone of proximal development, the sensitive periods of development, a social situation of development, a cultural and sign 
mediation of formation of the highest mental functions, the role of formation of an oral and written language for thinking, etc. For the development of all education system in Germany, L. S. Vygotsky's ideas about the role and value of cooperation of the child with an adult, children with each other, and teachers with each other became very important. So the social situation was developing. It means the situation itself should develop all the time (Ftenakis, 2015a).

In Iran, Saeednia (2011) was successful to implement the idea of creation of open educational space into practice, having created a network of cognitive schools. There, the cognitive interest of children in a zone of their proximal development, which is individual for each child, is stimulated and supported. During realization of this interest, children master cultural means of action and sign systems. They find new psychological tools. L. S. Vygotsky's works at these schools, as well as the works of J. Piaget and A. Maslou's works, are manuals for teachers.

In recent years in Russia, the new federal state educational standards (FSES) of the preschool, primary, main general, secondary general education are accepted. These standards are built in many respects in compliance with the scholar school of L. S. Vygotsky and his flock (Asmolov, 2013; Asmolov et al., 2008; Asmolov \& Kudryavtsev, 2016). Naturally, at the same time the question of training of teachers for the educational standards implementation became actual. This issue demanded the modernization of pedagogical education in compliance with the ideas put in FSES.

Since 2014, in MPSU, the group of developers has begun to build teacher training model (Bulin-Sokolov, Obukhov, \& Semenov, 2014), making a start from the idea that future teachers have to not only know works of L. S. Vygotsky and his his followers. Proceeding from the fact that "we learn as we were taught", they also have to live their own training in higher education institution as practice of realization of L. S. Vygotsky's ideas.

This teacher training model for practice of work in education system on requirements of the accepted FSES we, by using V. K. Zaretsky's concepts (Zaretsky, 2001), called it reflexive and activity approach in realization of pedagogical education (Bulin-Sokolov \& Obukhov, 2015).

The practical experience of training teachers on the basis of reflexive and activity approach, in compliance with the ideas of cultural and historical psychology of L. S. Vygotsky and scholar school has been implemented for three years. Quite a large number of students of a bachelor degree of pedagogical education take part in it, joining in this model from 1 course - about 2000 students of the following profiles of preparation: preschool education; primary education; teacher of the fine arts; teachers of physics and technologies; mathematics teacher and informatics; teachers of foreign languages.

For realization of this plan, we needed to form a team of adherents among the faculty who not just knew L. S. Vygotsky's works, but also were able to work in a paradigm of cultural and historical psychology. We began to solve this problem in continuous dialogue and cooperation - both with colleagues, and with students - in compliance with the ideas 
of social constructivism (Ftenakis, 2015b), involving all participants of educational process in the continuous event saturated business having the design forms of realization, creating and setting cultural forms of deployment of a reflection (Alekseev, 2002).

Proceeding from the idea of a functional frontage of reflexive processes (Karpov, 2005), this article is retrospective (on the bases, lying in the course of cultural and historical psychology of L. S. Vygotsky), situational (on the current situation of realization of these ideas in practice of pedagogical education) and a perspective reflection (on possible results and the expected effects for an education system taking into account obvious risks) concerning the process of modernization of pedagogical education on the basis of L. S. Vygotsky's ideas. We also made a start from the semantic course of the importance of the analysis of L. S. Vygotsky's ideas urgent for the development of children's practical psychology today offered by Dubrovina (2013).

The idea about development as about mastering culture.

The key idea of L. S. Vygotsky for psychology of development and psychology of education - the idea about sociocultural development of the child in ontogenesis. "We are inclined to put an equal-sign between the identity of the child and his cultural development. The personality, thus, is a social concept. It covers supernatural, historical component in the person. It isn't congenital, but results from cultural development. Therefore, personality is a historical concept. It covers the unity of behavior which differs in a mastering sign" (Vygotsky, 1983a, p. 315). According to L. S. Vygotsky, the process of cultural development includes mastering culturally-set means: 1 -actions with objects; 2 - relations with other people; 3 - possession of oneself, the mental activity, the behavior. Certainly, in this aspect the development of cultural means happens in ontogenesis. In youth, the means of selfcontrol accustom to that age period in which they are students. This includes the semantic fullness of the subject, the feature of the relations with other people and also at the age level in the context of the solution of urgent vital tasks. Such tasks are, in many respects, connected with the development of the subject maintenance of the future profession, and the social communicative space of a significant personal qualities of a profession. Naturally, the pedagogical profession in these aspects has the expressed specifics (Markova, 1993).

Three lines of mastering the culture allocated with L. S. Vygotsky, have become defining for us for designing the pedagogical education:

- Development of subject material (the subject module of the curriculum of vocational training) - that concreteness through which future teacher will build and realize practice of training and development with pupils. For future teachers of physics, mathematics, biology, chemistry, history, etc. - will be mastering subject knowledge and methods of knowledge acquisition in these or those subject domains which have developed and developing now in the corresponding branches of science;

- Development of psychology and pedagogical knowledge and methods of work with children of various age, taking into account specific and sociocultural features, and also with colleagues, parents and other participants of educational process (the psy- 
chology and pedagogical module of the curriculum). This module is built in logic of ontogenesis in process of the child's growing, from the preschool step of education to high school. In it, at a new stage of development of sciences about the child and processes of a growing the ideas, which have been put by K. D. Ushinsky in pedagogical anthropology (Ushinsky, 1867, 1869) are implemented, and after they are in their own way developed in pedology with active participation of L. S. Vygotsky (Vygotsky, 2001). That is the child process of his entry into culture studied in all aspects - physiological, psychological, social, pedagogical, pathological - taking into account the sociocultural situation of development;

- Application of funds of own cultural and personal development (sociocultural module of the curriculum). This module is directed into expansion of the cultural horizons, development of instruments of personal development (development of critical thinking within the course "Critical Thinking and Letter"; development of the corporality within the course "Pedagogical Thinking in Scenic Action"; development of modern information and communicative means as the new sign systems changing mentality and society; implementation of historical projects through which the judgment of concrete phenomena in the context of historical processes is developed, the skills of team work are fulfilled; and many other aspects which considerable part is implemented in the field of elective courses of students). The important component of this module is to support the student's social initiatives to get productive forms. The accounting of such activity happens through the submission of reflexive texts by students about the importance of their participation in this or that event for the professional and personal development.

Reorganization process became a natural problem, more precisely even creation of the new mode of work of teachers - when they don't conduct autonomous courses and when they have a need constantly to correlate the actions in respect of the students with other teachers, proceeding from an image of complete activities of the student for development of culture of a profession of the teacher. The classical high school system of the organization wasn't ready to it, and reorganization of any socially steady and inflexible system causes considerable resistance. Here, we see big risks: the integration processes which demand special efforts and the investments can progress from this or that degree of efficiency with the support "from above" and to joint deduction of a common goal "from below". Without it, processes of integration can sharply break as processes of separation and the centrifugal phenomena minimize the efforts of everyone in local timepoint. Besides, processes of integration happen in a situation of high trust between the participants of social processes that in a situation of changes and uncertainty can decrease rather, than increase (Golenkova \& Igitkhanyan, 1999), and very few people understand that integration processes in the long term can be advantageous for all together and for everyone as personal prospect.

Integrity of process of training through practice.

All three modules unite through practice begin with the first-year students. Practice allows through the organization of complete and system activity of the student in logic 
of the consecutive interconnected stages ( 1 - observation; 2 - pedagogical interaction; 3 pedagogical action) to embody in reality L.S. Vygotsky's idea that "the processes of training are considered [...] not as assimilation of elements and association of these elements in more or less difficult communications and as formation of complete structures without which no training is possible" (Vygotsky, 1972, p. 24). Integrity of educational process for the student goes through practice in logic "about actions to a thought", that is during acceptance and realization of problem tasks on practice, at students the request for the necessary theory which becomes for them the tool of reflection and planning of practical actions, as well as actually the content of interaction with children is formed.

The age as the basis of vocational education of the teacher.

The temporary sequence of deployment of training logic and practical actions of future teachers was defined by L. S. Vygotsky's idea about the value of child age in the general line of development: "A problem of age is not only central for all children's psychology, but also a key to all questions of practice" (Vygotsky, 1984, p. 260). Thus, students at first go for practice to preschool children, then to younger school students, then to teenagers.

L. S. Vygotsky's idea about the sensitive periods of development together with the line of age has allowed us to build contents of activity of students in practice in logic of "subject eras", the sequence of complication of forms and ways of activity.

So, on the "primary education" profile first-year students go for practice in the preschool educational organizations, developing the main lines of development in the preschool childhood, studying to interact with children in a zone of proximal development, studying the game and mastering the ways of enrichment of game activity, studying and putting knowledge into practice of a role of the developing subject environment for education of preschool children.

On the second-year students go to the first grade where they study the processes of adaptation of pupils to a new situation of development, promoting passing adaptation to school through the realization of the elements of the program of G. A. Zuckerman and K. N. Polivanova "Occurrence into school life" (Zuckerman \& Polivanova, 2003). From October to December, students teach in the first grade the subject "The World around" (Lovyagin, 2014) in logic of research and design methods of training that corresponds to urgent interests of pupils and sensitivity at this age and in this situation of development to development of new forms of the doctrine. The problem of development of a group work form and formation of a class as a group, the subject of educational activity is implemented (Zuckerman, 1980). The psychology of research behavior and feature development of research abilities in the course of formation of any and purposeful cognitive activity is studied (Obukhov, 2015; Poddiakov, 2006; Savenkov, 2006). In the 2nd grade, they begin to work with literary reading (Troitsky, 2004) through the semantic analysis of the text and staging. At the same time of the formation of the younger school ability, students start letter reading accompanying transition at them, from primary development of universal educational actions of reading and the letter to semantic work with the text (Elkonin, 1998). 
On the third year of training, students pass into the 3rd grade. They give classes in literature, mastering through the reflexive analysis of the translations, verbal games, etc. Basic properties of language, studying at the same time possibilities of formation of conceptual thinking master pupils reflexive abilities from external forms of the organization to the internal plan of reflexive action. In the 4th grade, students teach the course of applied mathematics (Semenov, 2004) within which children try to apply the mathematical apparatus mastered by them at mathematics lessons to the decision of vital tasks. On the course of it students try to understand how to develop logical thinking, understanding of sign systems, other aspects of thinking of pupils. In the long-term students shall go in the subsequent classes to see - that as well as why changes in development of children already at teenage years.

Being repelled from L. S. Vygotsky's idea that "[...] for any training they are separated, i.e. optimum periods. A withdrawal from them up or down, i.e. too early and too late periods of training are always from the point of view of development harmful, unfavorably reflected in the course of mental development of the child" (Vygotsky, 1996, p. 127) is in constant search - what object, methodical, psychology and pedagogical and sociocultural competence at what moment and in what sequence will be better mastered by students, taking into account the sensitive periods of development of children of those age groups to which they go on practice and the sensitive periods of development of pupils.

The main difficulties which overcoming we look for permanently is the fact that many questions can be mastered sequentially, and in practice all can be important at the same time. Everything can't be mastered directly, therefore, in what sequence, with focusing on what questions and problems shall happen to students taking into account the logic of development of children, on the one hand, and on the other hand - taking into account the logic of the subjects they teach at school.

Development of the personality is an integral process. At each age stage, it includes the development of informative and emotional and strong-willed processes, consciousness, self-standing and self-determination, many other aspects (Asmolov, 2002; Mukhina, 1999). Nevertheless, it is very difficult to master all the aspects at once and it is necessary to operate in logic of consecutive focusing, allocation of a dominant of attention on this or that aspect of development of the personality. Of course, there is a consecutive change of the leading activity that defines natural accents in studying with students of subject and manipulative activity, a game, educational activity, communication, etc. (Elkonin, 2001) in consecutive transition from one age step to another in practice. However, all these aspects of development of the personality and kinds of activity in one form or another are present at each age, that is also important to consider. Educational literature and classical logic of theoretical high school courses are most often built so that each aspect of a complete phenomenon - personality and its development - are studied and analyzed apart from each other.

In this regard, we see a natural problem of constant correction of creation of the sequence of contents and a form of work with students, and students with children at integration of subject, methodical, psychological and pedagogical aspects of professional activity. It 
raises an uncertainty situation in the course of development of a profession that demands transition of all participants of education from a position of the performer of the tasks set from the outside to a position of constant search, the reflexive analysis, changes of habitual plans, the critical relation to fulfilled to action forms, etc. Transition from the performer's position to a position of the director and the offtake of semantic tasks (under constantly changing conditions) is difficult and very few people are ready to it. However, "the abilities to set and the abilities to solve problems can unevenly grow or degrade: for example, the person can well learn to complete the tasks set by someone (to become the good performer) and to forget at the same time to see and set problems, to degrade as the potential director of tasks" (Poddiakov, 2015).

\section{Change of a social situation of development and crises of a growing.}

Immersion in a new social situation of development as crisis of a growing is the key for L. S. Vygotsky's idea about a social situation of development acts. "Environment for the person, eventually is the social environment because is where it acts even as nature. Nevertheless, in its attitude towards the person, it is available the defining social moments. In the attitudes of people towards it, they always use social experience" (Vygotsky, 1991, p. 88). At the same time for us, after L. S. Vygotsky, it is important to consider a social situation of development together with age: "Each age has the known image the environment organized for the child so the environment, in purely external sense of this word, changes for the child upon transition from age to age" (Vygotsky, 1966, p. 76). For us, it becomes essentially significant to fix both the attention, and the attention of students on in what measure this or that environment acts as a development source (where? whom? how? at the expense of what?), as "[...] the environment acts concerning the development of the highest properties, specific to the person, and forms of activity as a development source" (Vygotsky, 1966, p. 93).

Training students for pedagogical activity with children of this or that age, naturally, we have to consider also the age features of students. Most, it is important to do at occurrence their new social situation of the development of students, and also at identification with a new social role of the teacher. The idea that "at turning points of development, the child becomes rather difficult because change of the pedagogical system applied to the child doesn't keep up with rapid changes of his personality" (Vygotsky, 1984, pp. 252-253) fully belongs to students too. When there is a change of a social situation of development, there are new aspirations, requirements, opportunities. And the system of requirements, expectations, activity forms - new, not mastered yet is not appropriated.

We faced the choice: to soften the situation of adaptation to university with that process was most similar to previous - as at school. Or as much as possible, to use a situation of entry into a new situation of development for a changing a "scholastic" position which for most of students as it has been revealed, existed in passive forms of education, in a transmitting paradigm. Our choice was defined on the option of an aggravation of crisis of a growing at the organization of special maintenance of his passing to situations of adaptation of students to a new social situation of development. For this purpose, we have 
created the "Immersion in New Pedagogics" program which lasts for September. Its tasks are:

- Active entry of students into the new educational environment in which most part of the program demands from the student, not just hearing and watching, and action, interaction, creation various products in the form of the letter, a photo, video, etc.);

- Acquaintance to university as new social space of life through the system of search tasks, creative tasks, and social actions;

- Acquaintance to new and various forms of the doctrine to minimize lectures, and a variety of active and interactive forms of the organization training - workshops, excursions, games, discussions, and trainings;

- Expansion of the cultural horizons which is an exit out of limits of the developed stereotypes. This includes a variety of subjects, a meeting with bright and extraordinary people, not triviality of discussion known, original forms of representation of the unknown, an exit of process of the doctrine and activity in various cultural and social spaces, out of limits of university;

- Creation of a situation of the conscious choice with the responsibility for it. This requires every day the student to choose an occupation/seminar/action which will be interesting to him);

- Training the team work call student to do many tasks. Those tasks are set so that they can be realized only in group;

- Interactive communication of teachers. It involved experts and students, including in the information environment (INFODA MPSU on the basis of the Moodle platform - the virtual training platform on which teachers place tasks students in turn spread the performed works and receive feedback from teachers and each other, can finish and improve the works).

Refrain through all the Immersions programs there passes the question - "What is it to study?" We try to set representation to students not only about didactics (science how to learn), but also a Mathletics (science how to study). Bringing to understanding that we study first of all in active forms of activity, we find the ability to the development of the ability to study - through a reflection about process of the doctrine. The visualized information on implementation of this program is provided in the video blog of MPSU (http://video.xn--c1arjr.xn--p1ai/category/pogruzhenie-v-pedagogiku/).

\section{Ratio of training and development.}

Zone of urgent and proximal development. The central factor of the development cooperation. In domestic pedagogical psychology, it is accepted as the fundamental idea of L. S. Vygotsky that training leads development in a zone of the proximal development: 
“Developments don't coincide with training process ... developments go after processes of the training creating zones of the proximal development" (Vygotsky, 1983a, p. 51). This idea defines a trajectory of the movement on the way to individualization of educational process, the accounting of personal features of each pupil. "Pedagogical value of the concept "Zone of the proximal development" allows to answer a question of when there is a development at what moment this step - transition to new quality is made" (Zaretsky, 2007 , p. 96). The children of one age in the same educational situation can have this point at different time. In many respects, it is set by a social situation of development, unique for each child, - that system of the relations and interactions on significant others in which he is both objectively, and subjectively, and also his experience of activity and his individual inclinations and abilities.

"[... A An essential sign of training is that it creates a zone of the proximal development, i.e. brings it to life for a child, induces and sets a number of internal developments in motion. Now, for the child these processes are possible only in the sphere of relationship with people around and cooperation with companions, but, prolonging internal process, they become internal property of the child" (Vygotsky, 1991, p. 388). Proceeding from these ideas, we are from the very beginning of training of students immerse in situations in which they show borders of the zone of the proximal development. They realize limits of the opportunities. They find ways of cooperation with teachers and classmates as an extender of these borders and overcoming limits. Students appropriate a method of reflexive realization of an essence of difficulties in educational process and seize methods of an address request for the help in overcoming these difficulties. The "Immersing in New Pedagogics" program, and also specially entered course for first-year students - "Technology of personal development" is in many respects directed to it. After mastering on themselves the principle of development in cooperation, when overcoming urgent difficulties, students quit on practice and, first through observation over children, then through interaction with them - to build such method of creation of a pedagogical situation in which the zone of the proximal development of each pupil was considered. In case of frontal forms of operation, it can't be realized. Therefore, the key in mastering the pedagogical profession is mastering the methods of the organization of the group form of operation in which it can be implemented different forms of cooperation of children and the teacher, children with each other. We also understood that frontal forms of operation with students, that is a classical lecture, don't support this student's mode of work with children. After having saved continuous occupations, we rebuilt them in interactive forms of the training organization. Such occupations, approximately on 150-180 people, are built in a format of group operation. This group contains the general input at the beginning and the general reflexive final, with fixing and representation of different elements of process of operation or with its results by groups (or individually) in the information environment.

The teacher begins to execute here a role, not the role of the reader of the text who is already available to students in the information environment, and the moderator of group operation, the organizer of joint activities, proceed by the discussion and the analysis. The teacher doesn't give answers to all questions rather, and sets a problematic situation and gives instruments for its decision, showing - as norms of group operation step by step can 
be entered. And, after such cohabitation, students are offered to simulate group forms of operation with children, taking into account their age features and a personal zone of the proximal development.

In this situation students gradually begin to move with the idea about the need of the stringent scenario of occupation. In such way, teachers at schools usually implement considering only the sequence of presentation of a subject. But, he does not consider all variety of specific features of a zone of the proximal development of pupils in a class on the idea about need of sequential introduction of group norms of operation and a modelling of occupation taking into account specific features of children as well as the developed activities norms in group, the development of children solving problems by means of a subject, but not just broadcasting object knowledge

Transition to such model of pedagogical work, with a support on L. S. Vygotsky's ideas about training and development, centration on a problem of creation of problem situations and development of ability to cooperation at their overcoming, happens not so simply. We initially understood that standards of such work in mass educational practice are practically not observed. And we trained students that they will hardly see such standards at most of teachers as most of teachers prepared in a paradigm of influence and broadcasting, but not interaction and dialogue earlier. Initially students, having plunged into practice at school, really, have taken an isolation position from authoritative model of frontal work with a class, from centration on a subject, but not on problems of development of children.

However, the environment of school, comments and remarks of teachers, absence in classes in general of norms of group work that complicated use and realization of model of cooperation at one-two lessons when pupils are accustomed to other model of interaction with the teacher, gradually has caused identification with model of frontal broadcast of knowledge in many students. It has conflicted to the fact that at university, they were accustomed to model of the organization of educational activity in cooperation in a situation of overcoming problem tasks. Students, actually, have got into a situation of a social cognitive dissonance. Students had had an inquiry (even in the form of a claim that haven't taught it) - on a technique of the stringent scenario of class in one textbook, on one workbook, etc. (that there was no choice of problem, that there was no problem of own creation of the lessons).

To work on the set sample, without noticing complexity and - same it seems to instability of live systems more simply. For students, there was a question of the choice of model already not in words - and in the real strategy of own pedagogical action, in creation of own internal position of the professional. The students faced the problem of the valuable choice - to go on the way of conformism and to merge with the typical environment of school or to consciously accept a call of construction - the aligned training model, being in resistance with system. Understanding these risks and problems which have arisen on the middle of training of students at university, we began to work with student's phenomena of social psychology of education - pressure of the majority and minority, adoption of the group decision, cooperation and the competition, the personal choice, etc. We also constantly draw the attention of students to examples of discussions around progressive 
ideas in education in our country and in the world, to what has to be tomorrow, but not to what we can't get rid of. We observe that transition to variability of education as to "culture of advantage" happens not very simply - not only on social, but also at the individual level.

"Through the developing motivational and semantic variable education, the road from totalitarian culture of usefulness, culture of "the made heads", the identity of the person suppressing manifestations and beginning to be in agony in uncertain critical situations of different historical cataclysms, - to the culture of advantage maintaining identity of the person and by that possessing a wide reserve of non-standard social actions during various historical turns and dramas" runs (Asmolov, 2012, p. 240). We constantly draw the attention of students that centration on problems of development of the child, the training model as social constructivism is not just positive part of history of our domestic psychology, but also what became the basis of rapid development of variable models of education in the world. According to L. S. Vygotsky, "education is carried out through own experience of the pupil which entirely is defined Wednesday, and the role of the teacher at the same time comes down to the organization and regulation of this Wednesday" (Vygotsky, 1991, p. 85).

\section{Roundabout ways of development.}

Other problem field which for us was difficult is a training of students for work in a class with an inclusive situation. Initially we aligned attention of students to differentiations of so-called children with school difficulties (that is with adaptation problems, difficulties in regulation, etc., caused owing to inadequate actions of the teacher) and children with special opportunities of health and special educational needs. We have, in many respects solved this problem, having created a situation of the shipped observation of how there is a process of adaptation to school in 1 grade when students all September every day observed how the behavior of children depending on features of work of the teacher changes. However, in a situation of a real inclusion which became mass in educational practice we have faced other problem. So, the involved high-quality experts from the Center of Medical Pedagogics who are able to compensate very complex problems in development in children with the expressed special educational needs haven't given the answer to students on a question: What to do pedagogically when in a usual class there are such children? We have no experts owning from the teacher's position, methods of pedagogical work in an inclusion situation - in the country practically. And independent transfer of methods of work from specially organized conditions on a situation of a usual class - students aren't able to make and most often it is very difficult. The matter for ourselves is in a zone of the proximal development if not to tell - perspective. So far, we build in common with students a search algorithm of "roundabout ways of development" (Vygotsky, 1995), considering concrete difficult a case from student teaching, keeping the idea - making a start from what resources and the child's opportunities with special educational needs, taking into account the general situation in a concrete class. It is possible to promote as much as possible his inclusion in educational process. 


\section{Causal biography.}

L. S. Vygotsky's idea that for adequate identification of any manifestations of the child they need to be understood in development is especially significant for us. "The general and essential to drawing up scientific history of development of the child is the requirement that all this history of development and education was the causal biography. Unlike a simple story, from simple transfer of separate events (in one year there was that, and in another - something different) the causal description assumes such statement of events which puts them into cause and effect dependence, opens their communications and considers this period of life of the child as uniform, coherent, moving entity. Any new stage in development of the child needs to be understood as following with logical need from the previous stage" (Vygotsky, 1983b, pp. 303-304). From the very beginning of practice, we set a format of the observation of students of children prolonged in time. At the same time, it is observed with an obligatory video and the subsequent analysis which initial task is a distinction of objectively observed fact and its interpretation. Interpretation has to have justifications in the previous observed situations or become a hypothesis for further observations. And, taking into account conditional age norm, the student has to offer a reasonable explanation for observed manifestations of the child - as far as they are in limits of age norm on what signs, in what and why individual variations of manifestation of age norm of development are observed. The video has to reflect the child in kinds of activity, natural to his age. Interaction with peers and adults becomes an important aspect of the analysis of the recorded observation.

\section{The ideas about the highest mental functions and conceptual thinking.}

Development of a pedagogical profession in many respects is the development at the new level of the highest mental functions and the period of formation of professional conceptual thinking. We make a start from the fundamental idea of L. S. Vygotsky that "any highest mental function arising in the course of historical development of the person appears on the stage twice: at first as function of social and psychological adaptation; as form of interaction and cooperation between people, as the category of interpsychological; then - as a form of individual adaptation, as function of psychology of the personality, as the category of intrapsychological" (Vygotsky, 1960, p. 450).

Certainly, L. S. Vygotsky considered transformation of natural mental functions to the highest first of all as the process happening at early stages of ontogenesis. However, the "formula" presented in the quote in many respects in own way works when changing social development and need of development by the person of the new problems of social and psychological adaptation demanding new cultural means. We consider entry into a profession in many respects through development of system of concepts - as cultural tools of formation and organization of professional thinking. Our task - to accompany transition from everyday concepts to scientific. We adhere to L. S. Vygotsky's idea that scientific concepts aren't appropriated mechanically, by storing of abstract definitions: "aren't acquired and aren't learned by the child, don't undertake memory, and arise and develop by means of the greatest tension of all activity of his own thought" (Vygotsky, 1982, p. 198). We also share the idea that "the development of scientific concepts will rely by all means on 
the known level of maturing of spontaneous concepts" (Vygotsky, 1982, p. 199). Proceeding from it, we immerse students in practical pedagogical action (proceeding from the idea of development "from action to a thought"), step by step developing his professional conceptual thinking through a reflection on him:

- we ask to describe at first an observed situation by the own words, using in many respects everyday terms;

- we discuss a video of specific action with students, translating everyday concepts in scientific and gradually complicating and increasing a set of professional terms and concepts which give more differentiated and thin understanding of observed processes - in a live situation of communication of the person who speaks the professional language (teacher) with purposefully mastering this language (students);

- we ask to give and interpret the description of an observed situation with use of terms, presented in the concrete scientific literature offered students in the information environment;

- we ask to describe difficult, complex pedagogical situations on the professional language, solving also a problem of search of necessary theoretical literature for the adequate terminological description of the concrete situation recorded on video.

In this aspect, we are in constantly search optimum of a way, a phasing of complication and expansion of introduction of professional psychological terms that they became an important part of conceptual thinking of the teacher. In the long term, we plan to bring students to a position of the author's description of own researches or methodical developments with adequate and exact use of professional terminology of the - as the appropriated, natural language of the professional teacher understanding psychology of the child.

At this stage, we can tell only about the intermediate results reflecting effects of new model of training of the teacher on the basis of long ago known, but very urgent now, the ideas of cultural and historical psychology of L. S. Vygotsky. Most illustrative social effects which we had gained from employers - directors of the educational organizations. Many of them began to invite to work of our students who are only on their third year, and in certain cases - even on the 2nd year. At the same time, refusing employment of undergraduates and dismissing graduates of pedagogical universities who studied on the previous training model ("from the theory to practice"), finding in them, first of all, fear and inability to work with children in a situation of their natural unpredictability and variety in individual manifestations, and also inability to organize activity of pupils out of frontal forms of work (in an interaction paradigm, but not influences).

Exclusive concentration on broadcasts of a subject and deduction of the formal scenario of occupation, lack of social constructivism in practical work with children, inability to consider a zone of the next development of pupils - any more won't allow the graduate of pedagogical higher education institution to work according to new educational standards, 
won't meet the accepted professional standard of the teacher (Yamburg, 2014) by which directors a schoolbook with adequate and exact use of professional terminology of the language- as the appropriated, natural language of the professional teacher understanding psychology of the child begin to be guided.

\section{References}

Alekseev, N. G. (2002). Design and reflexive thinking. Development of the personality.(2), 85-102.

Asmolov, A. G. (2002). Psychology of the personality: principles of the all-psychological analysis. Moscow: "Sense", "Academy".

Asmolov, A. G. (2012). Education optics: Sociocultural prospects. Moscow: Education.

Asmolov, A. G. (2013). Variable education in the changing world: sociocultural prospect (theses about what to be to elementary school). Science and Education, 8(107), 3-13.

Asmolov, A. G., Burmanskaia, G., Volodarskaia, I., Karabanova, O. A., Salmin, N. G., \& Molchanov, S. V. (2008). Kak proektirovat'universal'nye uchebnye deystviya v nachal'noy shkole: ot deystviya $k$ mysli [how to project universal educational actions at elementary school: from action to a thought]. Moscow: Education.

Asmolov, A. G., \& Kudryavtsev, V. T. (2016). Preschool education in the mode of innovations. (1).

Bulin-Sokolov, E. I., \& Obukhov, A. S. (2015). Reflexive and activity model of training of the teacher for formation of the future. Science and School(6), 22-27.

Bulin-Sokolov, E. I., Obukhov, A. S., \& Semenov, A. L. (2014). Future pedagogical education. direction of the movement and first practical steps. Psychological science and education, 19(3), 207-226.

Davydov, V. V. (1996). The theory of the developing training. Moscow: Intor.

Dubrovina, I. V. (2013). L. s. vygotsky's ideas about the maintenance of children's practical psychology. Psikhologicheskaya Nauka I Obrazovaniye [Psychological Science and Education](3).

Elkonin, D. B. (1998). Development of an oral and written language of pupils / Under the editorship of V. V. Davydov. Moscow: INTOR.

Elkonin, D. B. (2001). Psychology of development of the person. Moscow: Aspect Press Publisher.

Ftenakis, V. (2015a). Need of changes: early education in the modern world. Obrazovatelnayapolitika, 4(70), 101-120.

Ftenakis, V. (2015b). With - designing: metodiko-didactic approach without passive participants. modern preschool education. Theory and practice, 2(54), 58-65.

Fthenakis, W. E. (2003). Zur neukonzeptualisierung von bildung in der frühen kindheit. In W. E. Fthenakis (Ed.), Elementary education according to pisa. how children's day centers can become educational institutions (pp. 18-37). Freiburg: Herder.

Galperin, P. Y. (1985). Methods of training and intellectual development of the child. Moscow: Publishing house MPSU.

Golenkova, Z. T., \& Igitkhanyan, E. D. (1999). Processes of integration and disintegration in social structure of the russian society. Sociological researches.(9), 27-34. 
Karpov, Y. (2005). The neo-vygotskian approach to child development. Cambridge: Cambridge University Press.

Lovyagin, S. A. (2014). How to make so that at school there were more good teachers of physics, chemistry and biology. Management of school(4), 23-24.

Markova, A. K. (1993). Psychology of work of the teacher: Book for the teacher. Moscow: Education.

Mukhina, B. C. (1999). Phenomenology of development and life of the personality: Chosen psychological works. Moscow: Moscow psychological-social institute, Voronezh: NPO MODEK.

Obukhov, A. S. (2015). Development of research activity of pupils. 2nd prod., republished. and additional. Moscow: National Book Center.

Poddiakov, A. N. (2006). Research behavior: strategy of knowledge, help, counteraction, conflict. 2nd prod., and additional. Moscow: PER SE.

Poddiakov, A. N. (2015). Training psychology in the conditions of novelty, complexity, uncertainty. Psychological researches. Online magazine., 8(40), 6.

Saeednia, Y. (2011). Self-directed learning among children of ages nine to eleven in tehran: Generating a persian version of sdlr-abe. US-China Educational Review, 8(12), 94-100.

Sakharov, T. N. (2016). The collection of reports on results of a scientific and practical conference "the person in the world of uncertainty: methodology of cultural and historical knowledge", dated for L. S. Vygotsky's 120 anniversary. Moscow: MPGU.

Savenkov, A. I. (2006). Psychological bases of research approach to training. Moscow: Axis-89.

Semenov, A. L. (2004). A modern course of mathematics and informatics at school. Questions of education(1), 103-118.

Troitsky, T. S. (2004). Literary education of younger school students. communicative and activity approach: Monograph. Moscow: Mnemozina.

Tulmin, P. (1981). Mozart in psychology. Philosophy questions(10), 127-137.

Ushinsky, K. D. (1867). Person as education subject. Volume I. SPb.

Ushinsky, K. D. (1869). Person as education subject. Volume II. SPb.

Vygotsky, L. S. (1960). The development of higher mental functions. Moscow: Publishing house of RSFSR.

Vygotsky, L. S. (1966). Lectures on pedology. Izhevsk: Publishing house Udmurt un-that.

Vygotsky, L. S. (1972). Structural psychology. Moscow: MSU.

Vygotsky, L. S. (1982). Collected works in 6 volumes. Vol. 2. Moscow: Pedagogika.

Vygotsky, L. S. (1983a). Collected works in 6 volumes. Vol. 3. Moscow: Pedagogika.

Vygotsky, L. S. (1983b). Collected works in 6 volumes. Vol. 5. Moscow: Pedagogika.

Vygotsky, L. S. (1984). Collected works in 6 volumes. Vol. 4. Moscow: Pedagogika.

Vygotsky, L. S. (1991). Pedagogical psychology / Under the editorship of V. V. Davydov. Moscow: Pedagogics.

Vygotsky, L. S. (1995). Defectology problems. Moscow: Education.

Vygotsky, L. S. (1996). Training and development at preschool age. Moscow: Publishing house of Shalva Amonashvili.

Vygotsky, L. S. (2001). Lectures on pedology. Izhevsk: Publishing house Udmurt un-that.

Yamburg, E. A. (2014). What the new professional standard of the teacher will bring to the teacher? Moscow: Education.

Zankov, L. V. (1985). Chosen pedagogical works. Moscow: Publishing house of Pedagogics. 
Zaretsky, V. K. (2001). About reflexive and activity pedagogics. In V. K. Zaretsky \& M. M. Gordon (Eds.), Summer school for children with features of development in nytvensky district: experience from 1996 to 2001 (pp. 29-41). Nytva.

Zaretsky, V. K. (2007). Zone of the proximal development: about what vygotsky hasn't managed to write.... Cultural and historical psychology(3), 96-104.

Zuckerman, G. A. (1980). Formation of educational activity in the collective distributed form (on material of experimental training of the native language at elementary school) (PhD dissertation). Moscow State University of Psychology and Education.

Zuckerman, G. A., \& Polivanova, K. N. (2003). Introduction to school life. program of adaptation of children to school. 2nd prod. Moscow: Genesis. 